\title{
LOCATING SINKHOLES IN LIDAR COVERAGE OF A GLACIO-FLUVIAL KARST, WINONA COUNTY, MN
}

\author{
Mina Rahimi \\ Water Resources Science, University of Minnesota, 173 McNeal Hall, 1985 Buford Ave., St. Paul, MN 55108, USA, \\ rahi0016@umn.edu
}

\section{E. Calvin Alexander, Jr.}

Earth Sciences, University of Minnesota, 310 Pillsbury Dr. SE, Minneapolis, MN 55455, USA, alexa001@umn.edu

\begin{abstract}
Sinkholes in Winona County, MN have been mapped four times since 1985 using different techniques including field observations, topographic maps, air photos and Global Positioning System (GPS) measurements. As of early 2009, these efforts had identified and inventoried 672 sinkholes in Winona County that are recorded in the Minnesota Karst Feature Database (KFDB) (See the KFDB at: http://deli.dnr.state.mn.us/). The acquisition of one-meter resolution Light Detection and Ranging (LiDAR) images has significantly increased the speed and accuracy of sinkhole mapping. One meter shaded relief LiDAR Digital Elevation Models (DEMs) for Winona County were visually scanned to compare sinkhole locations in the KFDB with the LiDAR images and to find new sinkholes in the LiDAR DEMs. The results of this method indicate that the number of actual sinkholes in Winona County could be as many as four times more sinkholes than identified by the preLiDAR surveys.
\end{abstract}

To automate sinkhole detection from LiDAR data at a regional scale, an algorithm was developed in MATLAB ${ }^{\circledR}$ based on image processing techniques. The algorithm has three steps. The first part detects potential sinkhole locations as depressions in the DEM using a morphological operation (erosion). The second part of the algorithm delineates sinkhole boundaries by automatically fitting an active contour (snake) around the potential sinkhole locations. In the last step, a pruning process, based on the relationship between depth and area of depressions, was applied to discard shallow depressions. The proposed method was evaluated on selected parts of Winona County. Evaluations of precision and recall returned positive results at $82 \%$ and $91 \%$ levels, respectively, which are sufficiently accurate to permit regional-scale, reconnaissance sinkhole mapping in complex landscapes.

\section{Introduction}

Sinkholes as surficial karst features can affect the water quality and quantity in underlying carbonate aquifers, as part of the hydrological cycle. Sinkholes have become convenient (but inadequate) indicators of the presence of karst processes/aquifers and are routinely used in zoning and resource management decisions by regulators. Complete, accurate inventories of sinkholes are therefore needed, but are difficult to produce and require ongoing updating.

Various techniques and methods are used to map sinkholes including topographic maps, air photo interpretation, and GPS measurements, as well as field observation. It is difficult to map all sinkholes using the above methods at a regional scale. For example, depending on the contour interval (map scale) on topographic maps, small- or medium-sized sinkholes are not detected. Also, sinkholes under forest often cannot be seen on the aerial photos. However, the recent availability of one-meter (elevation) resolution of DEMs derived from LiDAR has significantly increased the speed, accuracy and completeness of sinkhole mapping at the regional scale.

A simple method to map sinkholes using one-meter resolution of LiDAR data is to create hillshade images in the ArcGIS (ESRI, 2012) environment and then visually scan the hillshade image at varying resolutions to identify sinkholes. They can also be compared to air photos, available on such websites as Google Earth and Bing Maps. Although visually scanning is simple and accurate, it is laborious and time-consuming, especially for large regions. Also, sinkhole characteristics like area, perimeter and depth can only be measured or determined manually using visual techniques, which is very tedious and can be prone to accuracy problems. An automated method to locate and measure sinkholes from LiDAR data would significantly improve the speed and efficiency of sinkhole mapping from LiDAR data sets. 
Filin and Baruch (2010) proposed a method to automatically detect sinkholes and associated characteristics on a large scale. They detected the inner part of sinkholes using second-order partial derivates by arranging the Hessian form, $\mathrm{H}$.

$$
\mathbf{H}=\left[\begin{array}{ll}
\mathbf{Z}_{\mathrm{xx}} & \mathbf{Z}_{\mathrm{xy}} \\
\mathbf{Z}_{\mathrm{xy}} & \mathbf{Z}_{\mathrm{yy}}
\end{array}\right]
$$

where $\mathrm{Z}$ is the elevation from LiDAR DEM data. Then, they applied the active contour method (Kass et al., 1988) to delineate sinkhole boundaries. They used several validity tests, i.e. a compactness test and fitting a local bi-quadratic surface to the points surrounding the sinkholes for comparing the relative depth of inner point to adjust surface, to distinguish the sinkholes from shallow depressions.

\section{Study Area}

Winona County in southeastern Minnesota is part of the Upper Mississippi Valley Karst (Hedges and Alexander, 1985). Karst lands in Minnesota are developed in
Paleozoic carbonates and siliciclastics. As shown in Figure 1, the lower Ordovician Prairie du Chien Group, containing sandy dolomite and quartz sandstone, forms a karst plateau across much of Winona County. Most surficial karst features including sinkholes are only found in the areas where the sedimentary cover bedrock surface is less than $15 \mathrm{~m}(50 \mathrm{ft})$ thick (Figure 2).

The mapping of sinkholes in Winona County in southeastern Minnesota began in the early 1980s. Dalgleish (1985) conducted the first survey of sinkholes in Winona County as part of the Minnesota Geological Survey's development of the Geologic Atlas of Winona County (Balaban and Olsen, 1984). She identified 535 sinkholes in Winona County, many of which had been filled, using the traditional tools of field work, topographic maps and air photo interpretation. The sinkhole locations were compiled on paper 7.5' U.S.G.S. topographic quadrangles and, at a later date, digitized. Magdalene (1995) resurveyed sinkholes to update the sinkhole database in

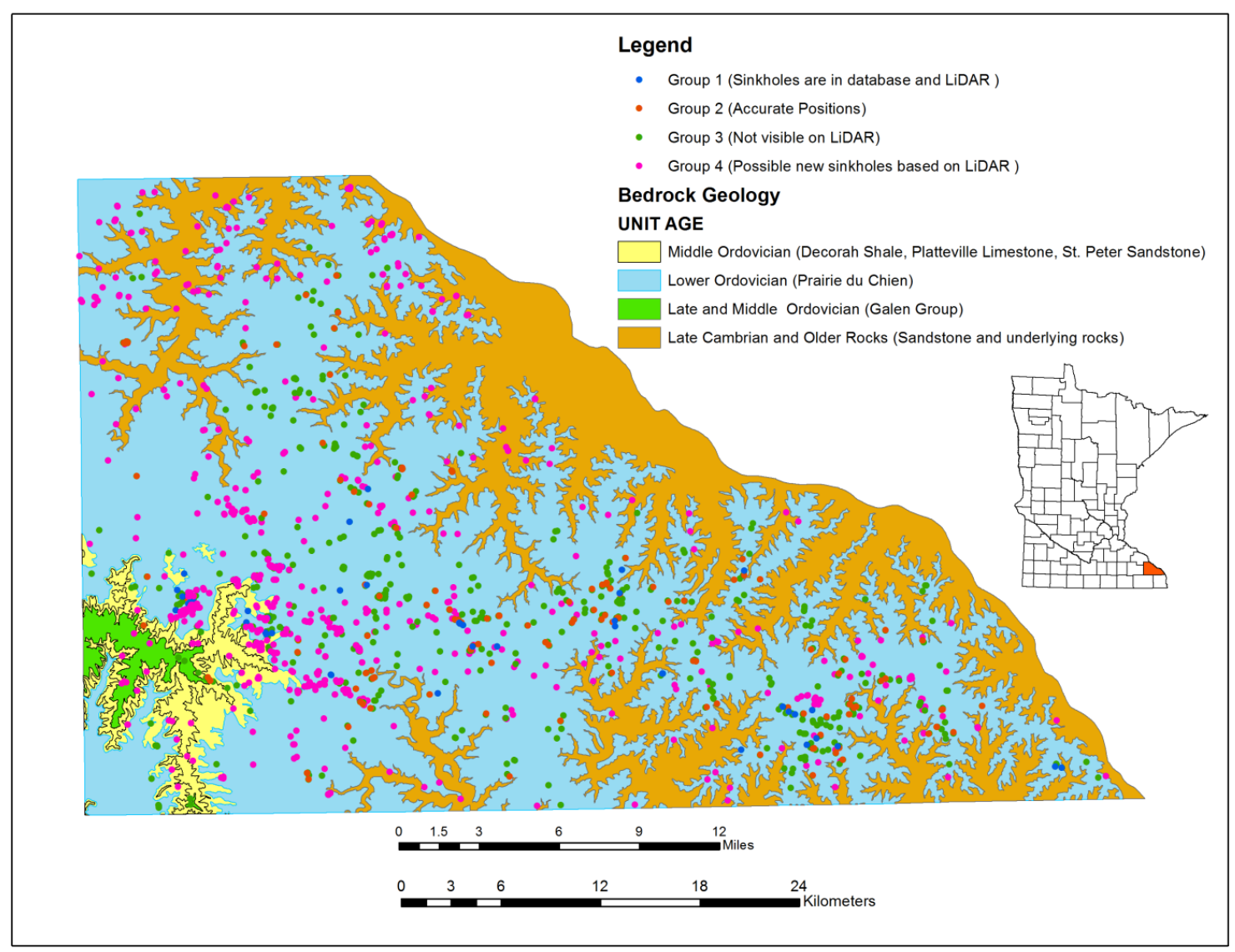

Figure 1. Bedrock geology and distribution of sinkholes in Winona County. 


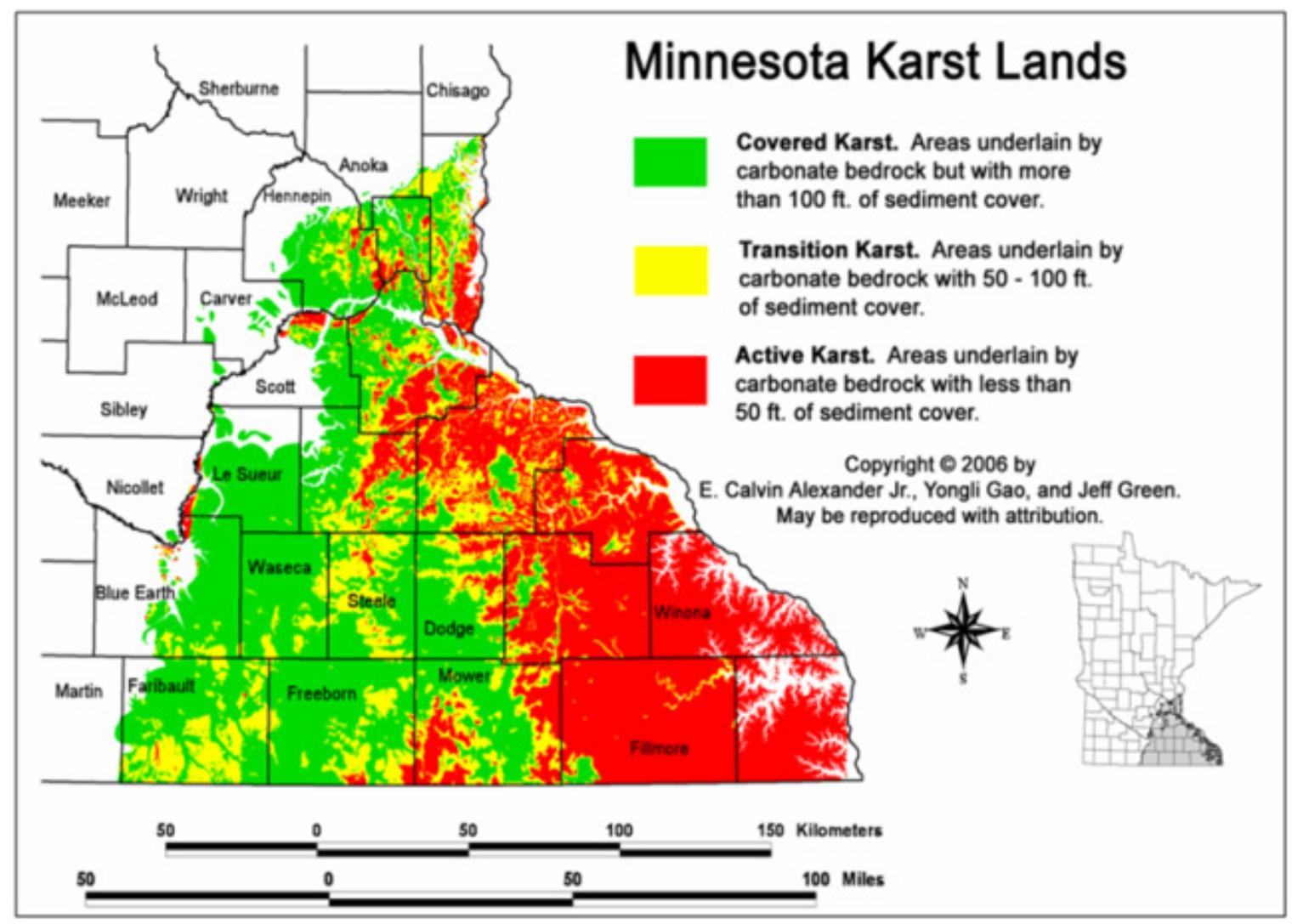

Figure 2. Map of Minnesota karst lands.

Winona County and recorded 72 more sinkholes. Gao and Alexander (2002) mapped additional sinkholes in Winona County using GPS technology.

Gao and Alexander also developed the Karst Feature Data Base (KFDB) for Southeastern Minnesota in a Geographic Information System (GIS) environment that includes sinkholes, springs, seeps, sinking streams and outcrops. The advent of GPS technology improved the accuracy of the more-recently inventoried sinkholes, but significant uncertainties remained in many sinkhole locations. Site specific field work added a few additional sinkholes to the KFDB, and 672 sinkholes had been inventoried in Winona County by early 2009.

This paper presents and compares two different methods to map sinkholes: 1) to visually scan LiDAR DEM images and 2) to develop an algorithm to automatically detect, delineate, characterize and validate potential sinkholes. The purposes of the first method are: 1) to compare sinkhole distribution in Winona County that had been mapped during previous decades with the new
LiDAR DEM images; and 2) to map new sinkholes using the LiDAR DEM images. The goals of the second method are: 1) to apply an algorithm to identify sinkholes automatically in some parts of Winona County; 2) to delineate sinkhole boundaries; 3 ) to determine sinkhole characteristics like depths, areas and perimeters; 4) to prune depressions which may not be true sinkholes from the list; and 5) to compare the results from processing the algorithm with the visually scanned datasets in the KFDB in order to evaluate the accuracy of the algorithm.

\section{Methods Visual Scanning of LiDAR DEMs}

Airborne LiDAR was flown over the study area between November 18 and November 28, 2008. The vertical accuracy is $0.161 \mathrm{~m}$ root mean square error (RMSE) at a 95\% confidence level (Loesch 2009).

One-meter shaded reliefs DEMs of Winona County derived from LiDAR were visually scanned at varying resolutions to identify sinkholes. As many as possible of the sinkholes in the early 2009 KFDB dataset have 
been relocated on LiDAR DEMs in ArcGIS to verify the sinkholes locations. In this process, additional sinkholes that were previously missed and new sinkholes which have opened since the original survey, were identified and mapped.

Air photos including Google Earth and Bing Maps proved valuable sources to help map sinkholes. Google Earth's coverage includes images from several different dates for some locations. "Birds eye" view feature from Bing Maps show low-angle, low-altitude, highresolution, pictometric photos from several directions for particular locations. Both types of coverage can be used visually to inspect the locations of sinkholes.

\section{Erosion and Active Contour Algorithm}

To automatically detect sinkholes and their boundaries, an algorithm in MATLAB ${ }^{\circledR}$ was developed based on image processing techniques. This algorithm has several steps: 1) detect local minimum points (seed points); 2) delineate depression outlines around each seed point; 3 ) characterize the perimeter, area and depth of each potential sinkhole; and 4) prune the list of potential sinkholes to differentiate sinkholes from shallow depressions that may not be true sinkholes. Finally, the remaining potential sinkholes were tested for validity as compared to known sinkholes that had been fieldchecked and entered into the KFDB.

The first step in the algorithm is to find local minimum points or the lowest point of depressions in LiDAR DEMs. The lowest point of depressions is identified through their geometric characterization using a

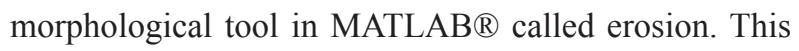
tool processes images based on their shape. It compares the value of each pixel in the input image with its neighbors and assigns the value on a corresponding cell in the output image. The morphological operation uses structural elements, called kernel windows, to define the neighbors. It can be a matrix with any size.

The erosion operation compares the cell value with its neighbors in the kernel window and returns the minimum value in it for that cell in the output image. Figure 3 explains an example of the erosion process. In Figure $3 \mathrm{~A}$ a schematic small depression is defined as a 5 by 5 matrix. Figure $3 B$ shows the position of a 3 by 3 kernel window as it moves across the input image. As seen in Figure 3B, the value of the first element in matrix is compared with the highlighted cells that are covered by the kernel window. After that, the minimum value of these cells is assigned for the first element in the output image (in Figure 3C). The kernel window shifts to the next cell and this procedure continues until it reaches the end of image. The final result of the eroded image is shown at Figure 3D. The lowest point of the depression can be identified by comparing each cell in the original image (Figure 3A) with the corresponding cell in the eroded image (Figure 3D). The cells with the same value are assigned 1 and those which have different values become 0. As shown in Figure 3E, the lowest part of the sinkhole has the value of 1 while its surroundings have 0 . Thus, the minimum point of the depression is located.

In this approach, the size of the kernel window influences the number of seed points identified. If the kernel window is too small, only a few cells are contributed and many local minima are identified. With a larger kernel window the number of cells included, the local minimum calculation increases and fewer seed points are identified.

Sinkhole depressions have various sizes and shapes, and they can sometimes be compound sinkholes: smaller sinkholes within a larger closed depression. Thus, to locate all of these depressions different sizes of kernel windows are needed; small kernel windows are optimal for small depressions and larger windows are better for larger depressions. Figure 4 shows the impact of the kernel window size on the number of seed points detected in LiDAR DEMs. Comparing kernel windows of 25 with 55 pixels illustrates that small depressions are detected with kernel size 25 while they are missed by kernel size 55 .
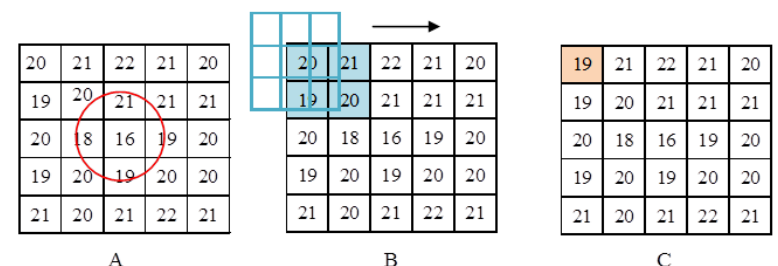

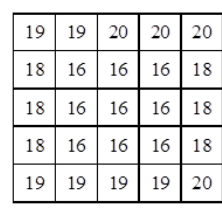

D

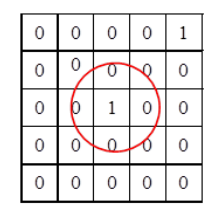

$\mathrm{E}$
Figure 3. The procedure of erosion function to find local minimum points. 

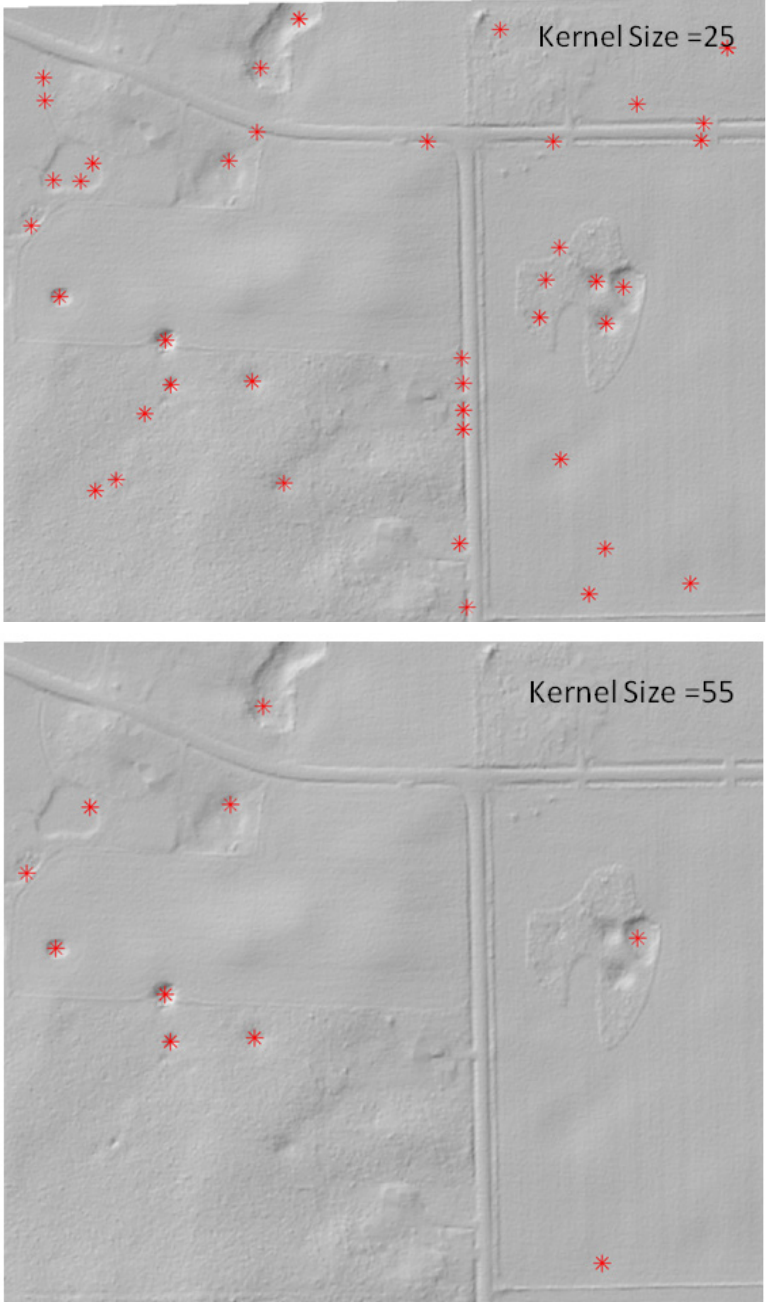

Figure 4. Effect of kernel window size on detecting seed points on LiDAR DEMs.

In the second step of the algorithm, an active contour, a method for delineating object boundary from an image, was used to identify the depression boundary of each of the seed points. The boundary is a closed curve that is determined based on changes in flow of the elevation gradient in the surrounding region around the seed point (Kass et al., 1988).

The gradient is directly derived from the elevation map shown in Figure 5 (top Figure). The magnitude of the gradient corresponds to the slope of the depression (i.e. white cells in the edge map, gradient map, shows the maximum slope of a depression). It is possible to fit a curve around the seed point passing through cells, each with a maximum gradient corresponding to maximum slope. This method, however, is known to be sensitive to initial conditions, such as initial radius, and the process may not converge to the actual boundary of the depression in many cases.

To address the convergence issues, $\mathrm{Xu}$ and Prince (1998) proposed a Gradient Vector Flow (GVF) that provides a more robust vector field based on the gradient. This vector flow function points toward the cells with
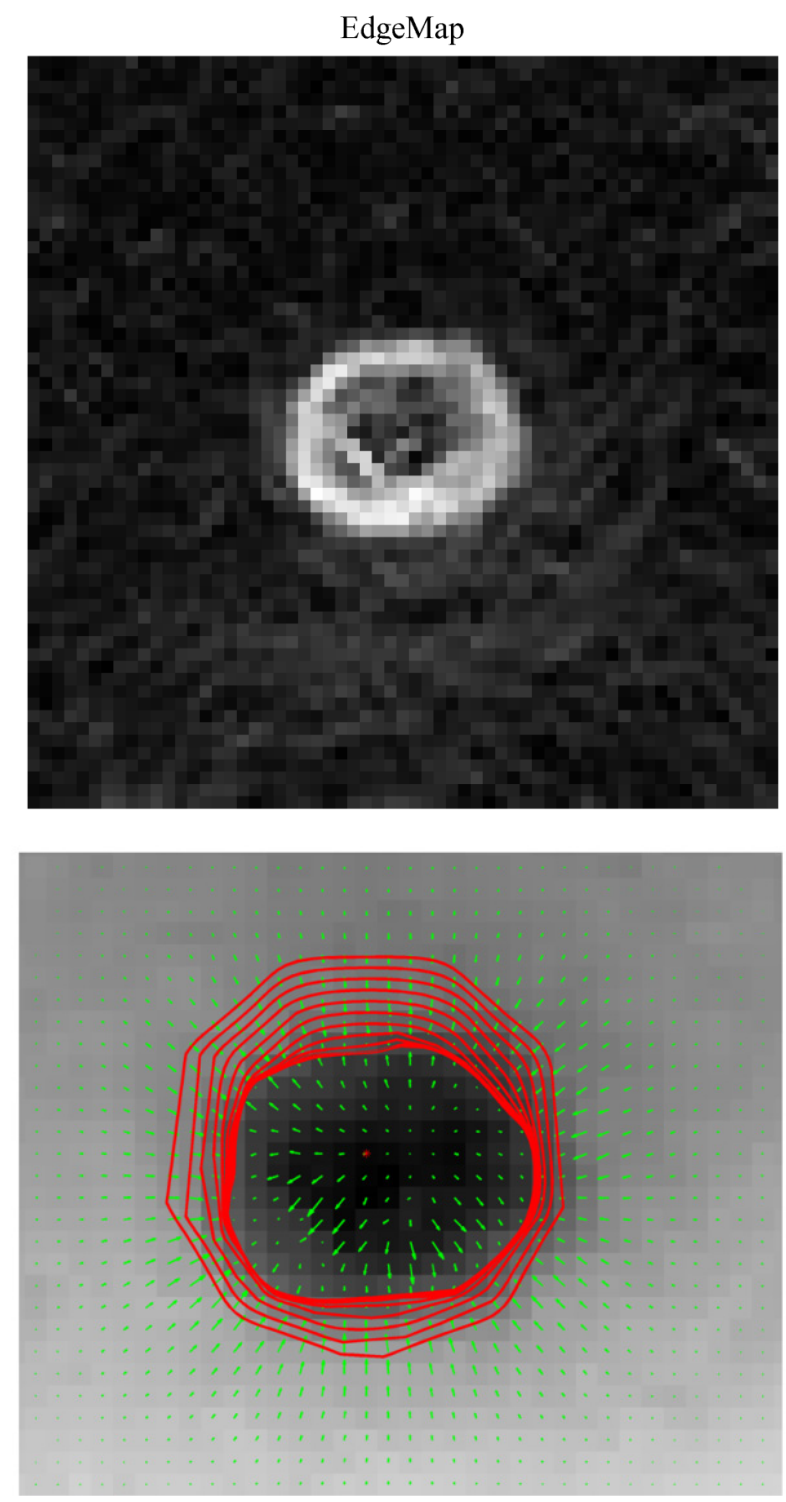

Initialization and iterative process results from active contour

Figure 5. In the EdgeMap, top figure, white cells correspond to the maximum slope of a sinkhole. In the bottom, the green vectors are determined by Gradient Vector Flow. These vectors point toward the edge of the sinkhole boundary where there is maximum slope. The red contours show initialization and iterative processing until the contours converge to the sinkhole boundary. 
maximum slope, even in regions far from the depression's boundary. Figure 5 shows an example of an EdgeMap, and the output for GVF of a sinkhole. As evident in this figure, flow vectors point toward the edge of the depression boundary where the slope is maximized. Also, it is shown that in homogeneous regions where the gradient barely changes, the vector flow is nearly zero.

An active contour is a curve that fits pixels of an image where a provided energy function is minimized. In this application, the energy function is (partially) chosen to be the GVF, and therefore, once the active contour converges, it finds the locations around a seed point where the slope is at its maximum. As presented below, two parameters influence the curve movement in the active contour (Xu \& Prince, 1998): a) internal forces coming from the curve itself and b) external forces extracted from the image data (i.e., GVF in this application)

$$
\mathbf{E}=\int_{0}^{1} \frac{1}{2}\left[\boldsymbol{\alpha}\left|\mathbf{X}^{\prime}(\mathbf{s})\right|^{2}+\boldsymbol{\beta}\left|\mathbf{X}^{\prime \prime}(\mathbf{s})\right|^{2}\right]+\mathbf{E}_{\mathrm{ext}}(\mathrm{X}(\mathrm{s})) \mathbf{d s} \text { (Eq.1) }
$$

Where $\mathrm{E}$ is the total energy function, the external energy is determined from the GVF: $=-f(x, y)$. The remainder, the interal energy function, controls the behavior of the curve. In particular, the selection of $\alpha$ and $\beta$ (components of internal energy) determine the tension and rigidity of the curve. The tension parameters control how much force is exerted on the contour to make it smaller. The rigidity parameter controls the smoothness and bending of the contour. Finally, is a contour location defined as . The active contour is solved iteratively, and therefore it needs initialization. The bottom image in Figure 5 shows the iterative process to delineate a sinkhole boundary. Also note the better definition of the sinkhole boundary by the active contour function, compared with the EdgeMap.

\section{Sinkhole Characterizations}

Given the boundary of the depression, the depth, area and perimeter can be calculated for each individual depression automatically.

To calculate the perimeter, the distance formula is used:

$$
\mathbf{P}=\sum_{\mathbf{i}=\mathbf{1}}^{\mathbf{n}} \sqrt{\left(\mathbf{x}_{\mathbf{i}+\mathbf{1}}-\mathbf{x}_{\mathbf{i}-\mathbf{1}}\right)^{2}+\left(\mathbf{y}_{\mathbf{i}+\mathbf{1}}-\mathbf{y}_{\mathbf{i}-\mathbf{1}}\right)^{\mathbf{2}}} \text { (Eq. 2) }
$$

where $\mathrm{P}$ is perimeter for the individual depression, $\mathrm{n}$ is the number of boundary points, and and are the coordinates of the boundary points. As the LiDAR data has one-meter resolution, the area is simply computed by counting the number of pixels which are located inside the perimeter. Another parameter, depth, is determined by subtracting the median of all of the pixel values along the perimeter from the pixel value of the seed point. The formula is as follows:

$$
\text { depth }=\mathbf{z}_{\text {median perimeter }}-\mathbf{z}_{\text {seed point }} \text { (Eq. 3) }
$$

where $\mathrm{z}$ is the elevation value derived from LiDAR data.

\section{Pruning}

The algorithm finds all local depressions in LiDAR DEMs. Filin and Baruch (2010) suggest different validity tests to separate local and shallow depressions from true sinkholes. One test is compactness. For example, as sinkholes often follow a circular shape, the only candidates accepted as sinkholes are those contour lines whose compactness is nearly 1 (i.e., close to a circle).

However, the compactness test could not apply in many Winona County sinkholes due to their irregular shapes. A significant number of true sinkholes will be eliminated if the compactness test is used in Winona County. So, another method is required to prune these shallow depressions.

To find a threshold for pruning, a typical area of Winona County which contains the most representative topography and sinkhole shapes was selected.

In the selected area, typical sinkholes were manually identified to determine the relationship between their area and depth. For each sinkhole, the perimeter was marked by drawing a polygon. Based on the polygon, the area of the sinkhole was calculated. Then, the depth of the sinkhole was obtained by subtracting the elevation of the deepest point within the polygon and the median elevation on the sinkhole's perimeter.

This "training" dataset was used to identify extreme sinkholes in terms of their size and depth. Two types of such sinkholes are defined: 1) The sinkholes with depths of at least $90 \%$, compared to the depth of the shallowest field-mapped sinkhole, and 2) the sinkholes with depthto-area ratios of at least $90 \%$, compared to the fieldidentified sinkhole with the smallest depth-to-area ratio. Using these two extreme types of sinkholes (see Figure 6), a minimum depth-to-area ratio test is established by passing a line through the two extremes. In the pruning 
step, those candidates whose depth vs. area falls below the depth-area extreme line are removed.

In order to increase the recall rate (Table 1), (possibly at the expense of decreasing the Precision rate), the $y$-intercept of the extreme line may be tuned such that all the extreme sinkholes (in the training dataset) are located above the test line. This is particularly important for sinkholes with small areas that are in the early stages of development, and thus their shallow depth may place them below the test line. To accommodate for these sinkholes, the y-intercept of the test was decreased by 0.1 meters for sinkholes whose areas were lower than 100 square-meters. For example, in the case of a sinkhole with an area of 100 square-meters and a depth of 0.36 meters, it will not be discarded, based on the test line. But, in the pruning, sinkholes with areas of less than 100 square-meters and depths of less than 0.26 meters will not be included in the inventory.
To evaluate this threshold, a smooth region with no sinkholes was selected and the algorithm was run (Figure 7). As expected, many depressions were detected. However, after pruning about $92 \%$ of them were eliminated. The three remaining depressions, False Positive (FP) points, are ponds behind artificial dams. This example clearly shows that the threshold works well.

\section{Results and Discussion Visual Scanning of LiDAR DEMs}

The previous mapping of Winona County sinkholes had recorded 672 in the KFDB through 2009. Table 2 compares the Winona County sinkhole data in the 2009 KFDB and the results of visual scanning of the Winona County LiDAR data set. The data produced four distinct groupings.

Group 1: 66 sinkholes had LiDAR locations the same as their KFDB locations. These sinkholes served as

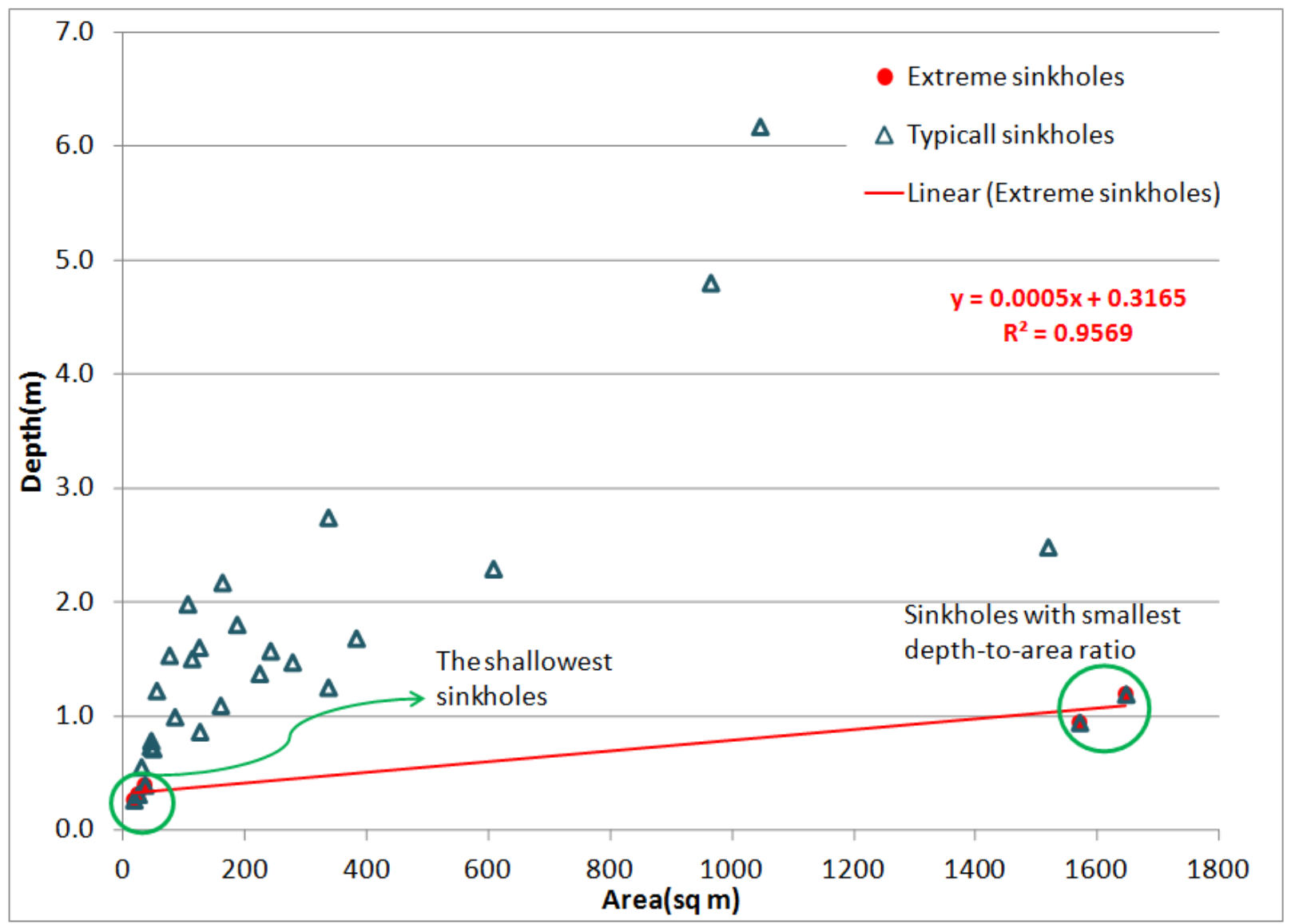

Figure 6. Two extreme sinkholes in terms of depth and area are identified. The first extreme, in the lower left, are the sinkholes with depths of at least $90 \%$ of the shallowest sinkhole. The second extreme, in the lower right, are sinkholes with depth-to-area ratios of at least $90 \%$ of sinkholes with the smallest depth-to-area ratio. 
Table 1. The definition of recall and precision.

\begin{tabular}{|l|}
\hline True Positive (TP): Corrected results \\
\hline False Positive (FP): Unexpected results \\
\hline False Negative (FN): Missing results \\
Precision $=\frac{\text { TP }}{\text { TP }+ \text { FP }}$ \\
Recall $=\frac{\text { TP }}{\text { TP }+ \text { FN }}$ \\
\hline
\end{tabular}

Table 2. Comparison of the original KFDB with the LiDAR Sinkhole Data.

\begin{tabular}{|c|c|c|c|}
\hline \multicolumn{3}{|c|}{ Sinkholes in 2009 KFDB } & \multirow{3}{*}{$\begin{array}{l}\text { Sinkholes } \\
\text { visible in } \\
\text { LiDAR but } \\
\text { not in KDFB }\end{array}$} \\
\hline \multicolumn{2}{|c|}{$\begin{array}{l}\text { Visible in the LiDAR } \\
\text { DEMs }\end{array}$} & \multirow{2}{*}{$\begin{array}{c}\text { Sinkholes } \\
\text { not visible } \\
\text { in LiDAR } \\
\text { DEMs }\end{array}$} & \\
\hline $\begin{array}{c}\text { Location } \\
\text { not } \\
\text { adjusted }\end{array}$ & $\begin{array}{l}\text { Location } \\
\text { adjusted }\end{array}$ & & \\
\hline Group 1 & Group 2 & Group 3 & Group 4 \\
\hline 66 & 168 & 439 & ------ \\
\hline \multicolumn{3}{|c|}{672} & 651 \\
\hline
\end{tabular}

important learning tools. They helped to illustrate what Winona County sinkholes look like in LiDAR DEMs in terms of shape and size.

Group 2: 168 sinkholes are visible in the LiDAR DEMs, but at slightly different locations than were recorded in the KFDB. The difference in locations was attributed to location errors in the KFDB. The old data was explicitly known to have location errors up to hundreds of meters. LiDAR allowed determination of more accurate locations for those sinkholes and to quantify the location uncertainty in the earlier data. The range of relocation adjustments was between 1 to 180 meters. Most of the location corrections were in the 10- to 30- meter range (Figure 8). Sinkhole location errors in the pre-LiDAR data included field location errors, changes in projection from NAD27 to NAD83 and accumulated typographical and transfer errors in $30+$ years of record keeping (through several generations of data storage media). Quantification of these location errors was important in the definition of Group 3.

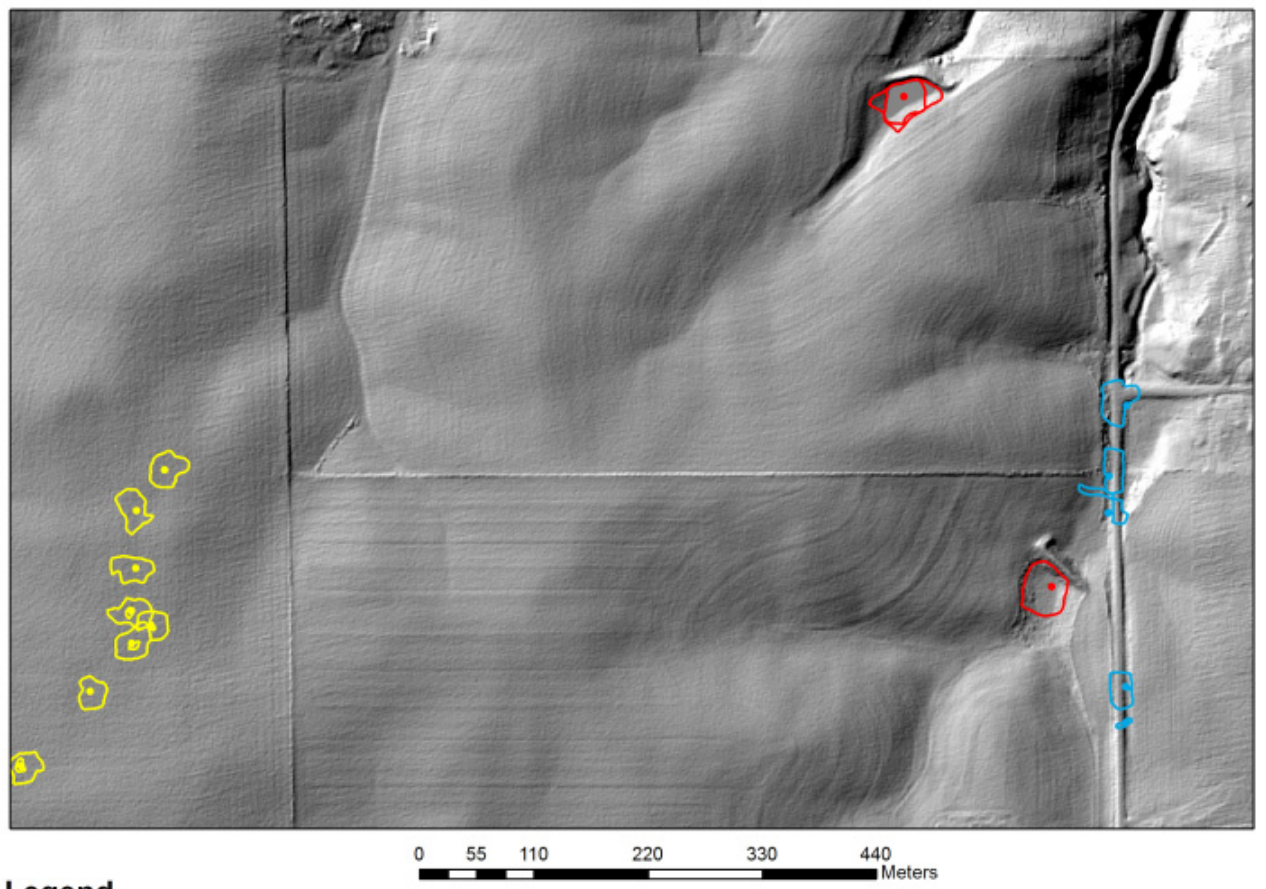

Legend

\section{Seed points}

- False Positive (FP) points that will be remained after pruning Shallow depressions that will dicarded after pruning

- Points near road that will be removed using buffer
Figure 7.

Yellow points are identified as shallow depressions by pruning so they are removed from inventory. These points are located below the test line in Figure 6. Points in blue are depressions near the road. They are removed by the buffer tool in ArcGIS. The red points are False Positive (FP) points. They are located above the test line but they are not sinkholes. They are ponds behind dams or in ditches. 


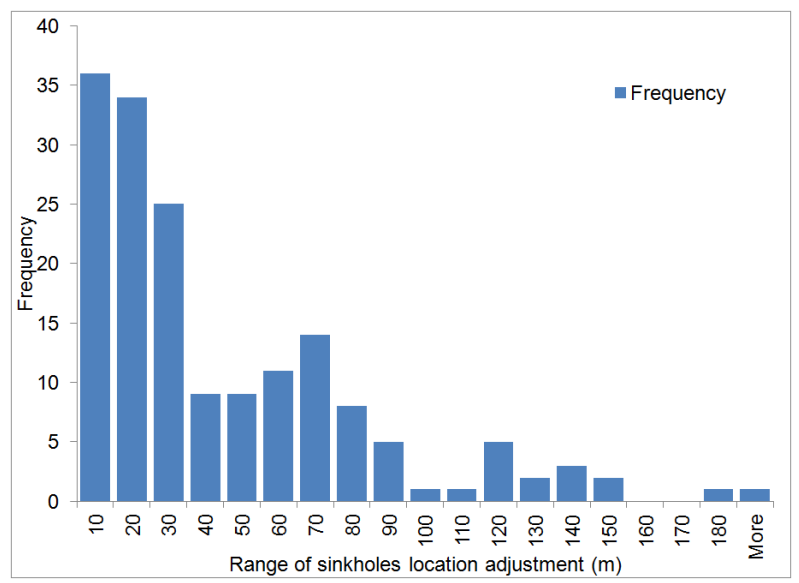

Figure 8. Histogram of the relocation distance.

Group 3: 439 (65\%) of the sinkholes listed in the KFDB were not visible on the hillshade derived from LiDAR DEMs. Approximately two-thirds of the inventoried sinkholes have apparently been filled for agricultural use and other reasons. Some of the filled sinkholes, not visible on LiDAR, can be seen on aerial images. Because filled sinkholes have a thicker profile relative to the surrounding, visible soil moisture contrasts are detectable on aerial images under the right moisture stress conditions. As illustrated in Figure 9, sinkhole D0019 has been filled and is not visible on the LiDAR or the Bing Map, "bird's eye" view feature. However, D0018 and is seen on the Bing map but it is not visible on LiDAR.

Group 4: The high resolution of one-meter LiDAR DEMs facilitates the mapping of sinkholes with high accuracy and precision. The LiDAR covers the entire region, including many areas previously unsearched by field work, and thereby provides a synoptic view of the entire county. In Winona County 651 potential new sinkholes, not listed in the KFBD, have now been mapped, as shown in Figure 1. Field checks are necessary to verify which LiDAR features are sinkholes and which are other features. If all of these features are sinkholes, they will nearly double the number of mapped sinkholes in Winona County. If the ratio of two filled sinkholes for each currently open sinkhole holds, then Winona County may have up to four times as many sinkholes as are listed in the KFDB, based on visual mapping.

\section{Erosion and Active Contour Algorithm}

A small region of southwestern of Winona County, Minnesota was selected to evaluate the best parameters for the active contour method including examining the initial radius. As mentioned in the method section, the active contour is solved iteratively and then it needs initialization. Therefore, an initial radius is defined around each seed point and an iterative process finds the boundary around the seed point.

As seen in Figure 10, the sizes and depths of depressions range from very small ones with depths of less than 0.21 meter to very large ones with depths of 1.5 meter and greater. With this variety of sizes and shapes, it is impossible to identify all of the depressions with only one parameter. Therefore, different sets of parameters were examined and three of them were selected. The first parameter set uses a large kernel window size and the largest initial radius $(15 \mathrm{~m})$ for the active contour. This parameter set detects large and deep depressions. The second set, with the same kernel window size but different initial radius $(10 \mathrm{~m})$, identifies medium and shallower depressions. The third set with the smallest kernel window size and initial radius $(5 \mathrm{~m})$ is able
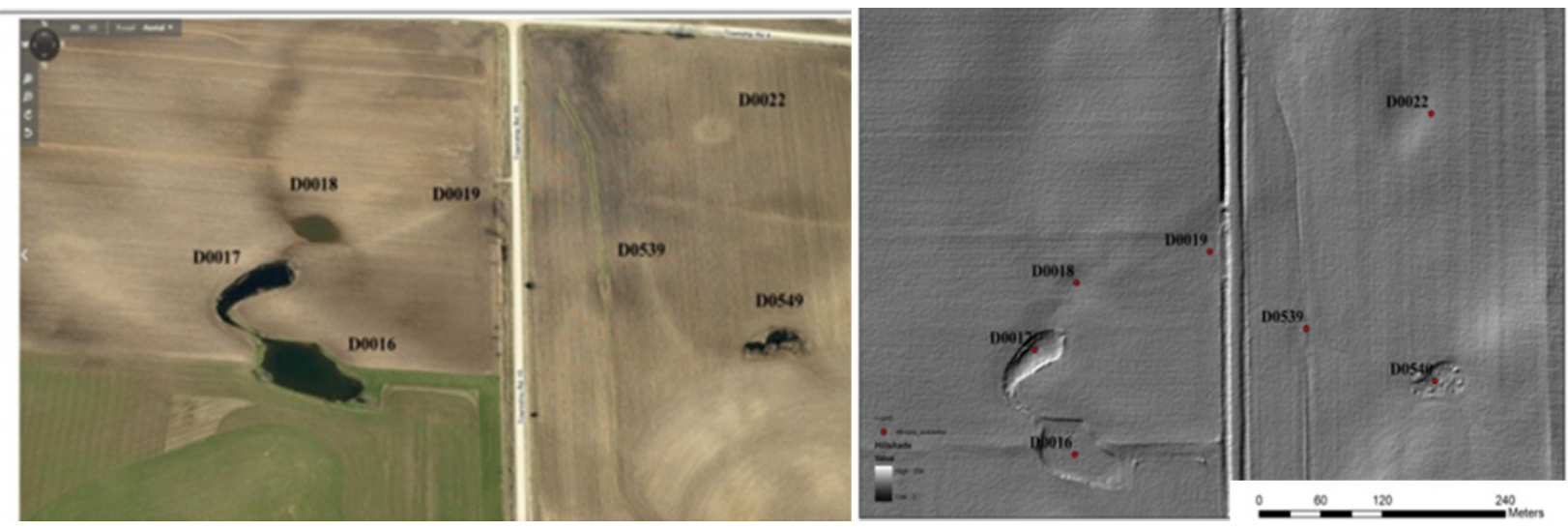

Figure 9. Comparison of sinkholes that is visible on Bing map and on LiDAR. 


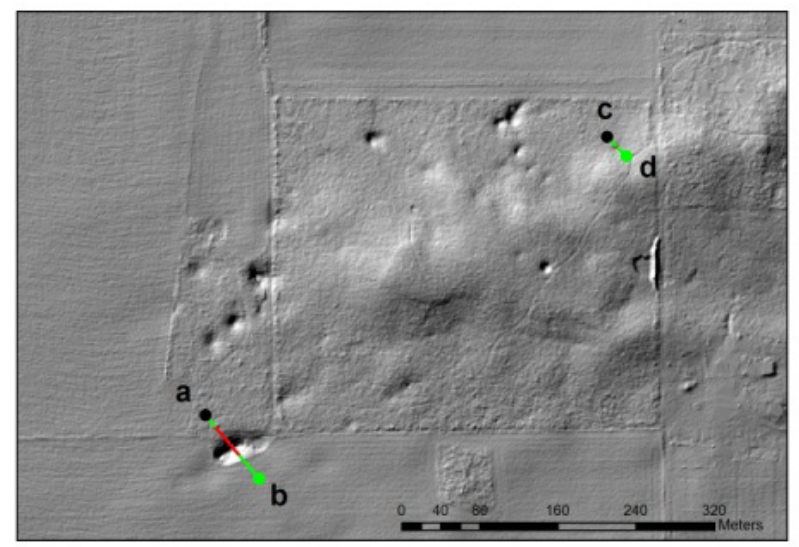

Figure 10. Sinkholes in Winona County have various size and shape range from very shallow and small to very large and deep.
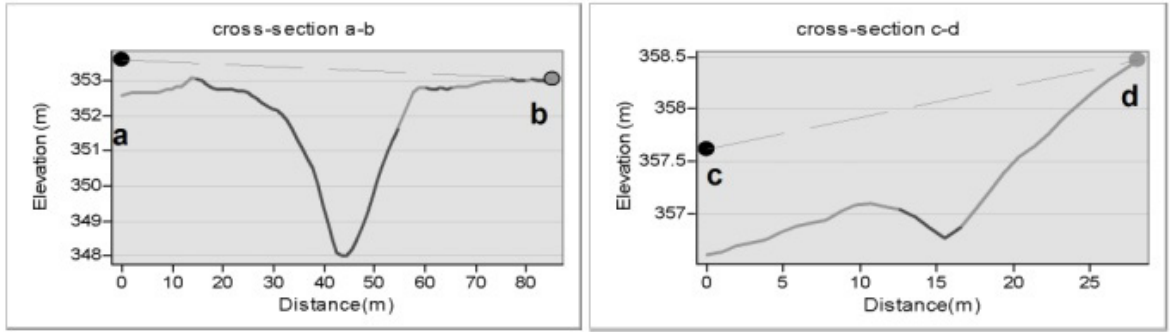

to identify very small and shallow depressions. To validate the latter, the DEM in ArcGIS was resampled from 1-meter resolution to the finer resolution of 0.5 -meter to detect very small and shallow depressions.

The problem of small depressions is that gradient changes are very smooth so that they cannot be easily identified with the 1-meter DEM resolution. In other words, there is no sharp transition from the minimum point of depressions toward their surroundings. However, with finer resolution, the gradient changes are more distinct, so the active contour method can identify the boundary for more shallow and small depressions. Figure 11 illustrates an example of three parameter sets for the active contour function. As Figure 11 shows, the parameter set 3 converges to depression boundaries better than parameter sets 1 and 2. This example clearly shows how the larger initial radius produces a better match with the depression boundary where the depression is large.

\section{Validity test}

To assess the precision of these methods, including erosion, the active contour, and this threshold procedure, 11 different parts of south-western Winona County with sinkholes of various sizes and shapes were selected and the procedures were run.
Results show pruning removed significant number of shallow depressions; however, some of them have remained. The remaining points after pruning are not true sinkholes; they are ponds behind dams, depressions in ditches, local depressions in quarries and points near stream beds or roads (Figure 12). Note that points near roads are removed using a buffer tool in ArcGIS, so they are not counted in calculating precision and recall.

As seen in Figure 7, most of the depressions are shallow local depressions (less than 0.15 meter depth). Such shallow depressions are farmed across and are typically not considered sinkholes by the landowners. However, they

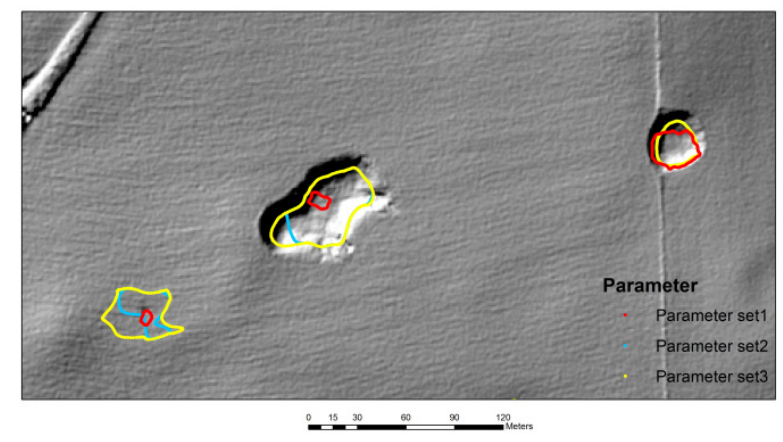

Figure 11. Three different parameter sets for active contour. The red has the initial radius $(5 \mathrm{~m})$, the blue has the initial radius $(10 \mathrm{~m})$ and the yellow has the initial radius $(15 \mathrm{~m})$. 

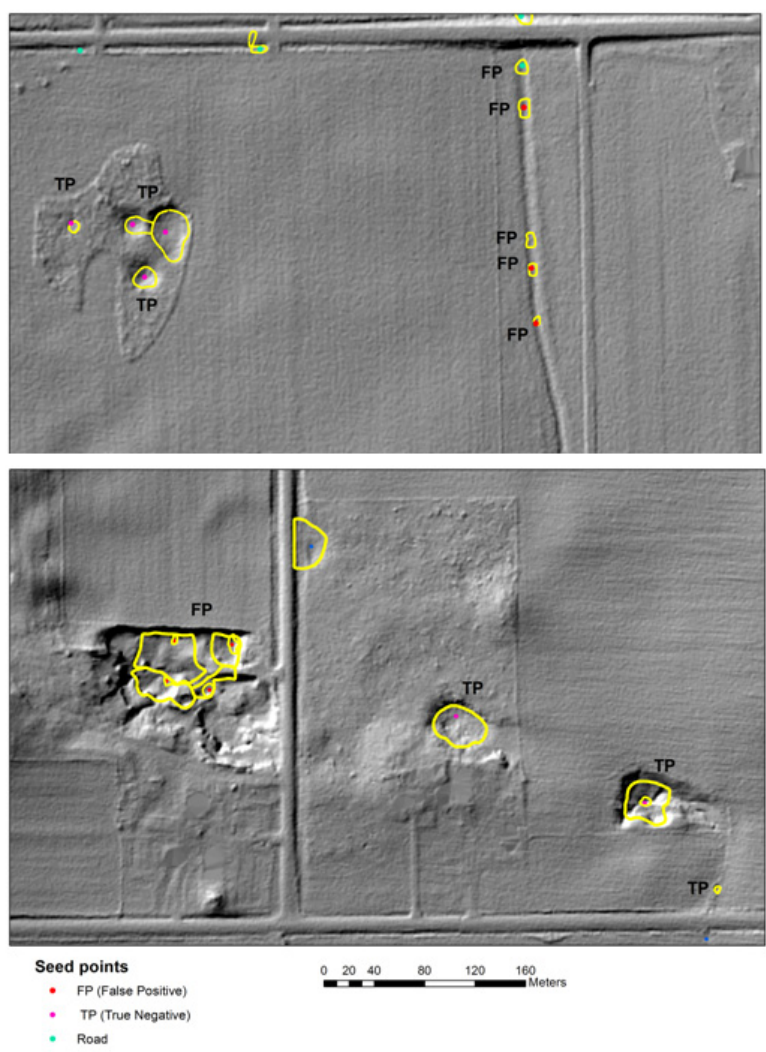

Figure 12. Local depressions have remained after pruning that called False Positive (FP). They are located in ditches and quarries.

may be filled paleo-sinkholes or new subsidence sinkholes, or maybe the result of non-karst processes. Thus, a method to isolate these subtle local depressions was needed.

Although pruning discards most of shallow depressions, true sinkhole may also be removed. Based on the threshold, sinkholes with area larger than 600 square-meters and depths of less than 0.6 meter are removed. In Figure 13, a sinkhole with an area of 1800 square-meters has a depth of 0.46 meter: so it plots below the test line in Figure 6 and is eliminated. However, the number of true sinkholes which are discarded by this pruning is very low compare to the number of shallow depressions defined.

After pruning, the results show out of 127 initial sinkholes identified, 97 of them were detected correctly, based on field-verified data in the KFDB. These are called true positives (TP). Of that sample, 21 of them are false positives (FP), which mean they are not sinkholes but have remained after pruning. The majority of these points are located in ditches and quarries. The remaining 9 sinkholes were not detected by these methods or were discarded by pruning. These are called false negatives (FN). Consequently, the precision and recall results were calculated for the algorithm.

The precision for the selected region in southwestern Winona County is $82 \%$. This means that $82 \%$ of the detected sinkholes are true sinkholes, and the remainders are false positives. The recall is $91 \%$, which indicates this method only misses $9 \%$ of sinkholes.

Considering the heterogeneity of Winona County (complex topography, woods, quarries, natural watercourses, man-made features, etc.) the algorithm method works wells to detect sinkholes. This automatic method can be refined using human supervision to increase the precision and recall.
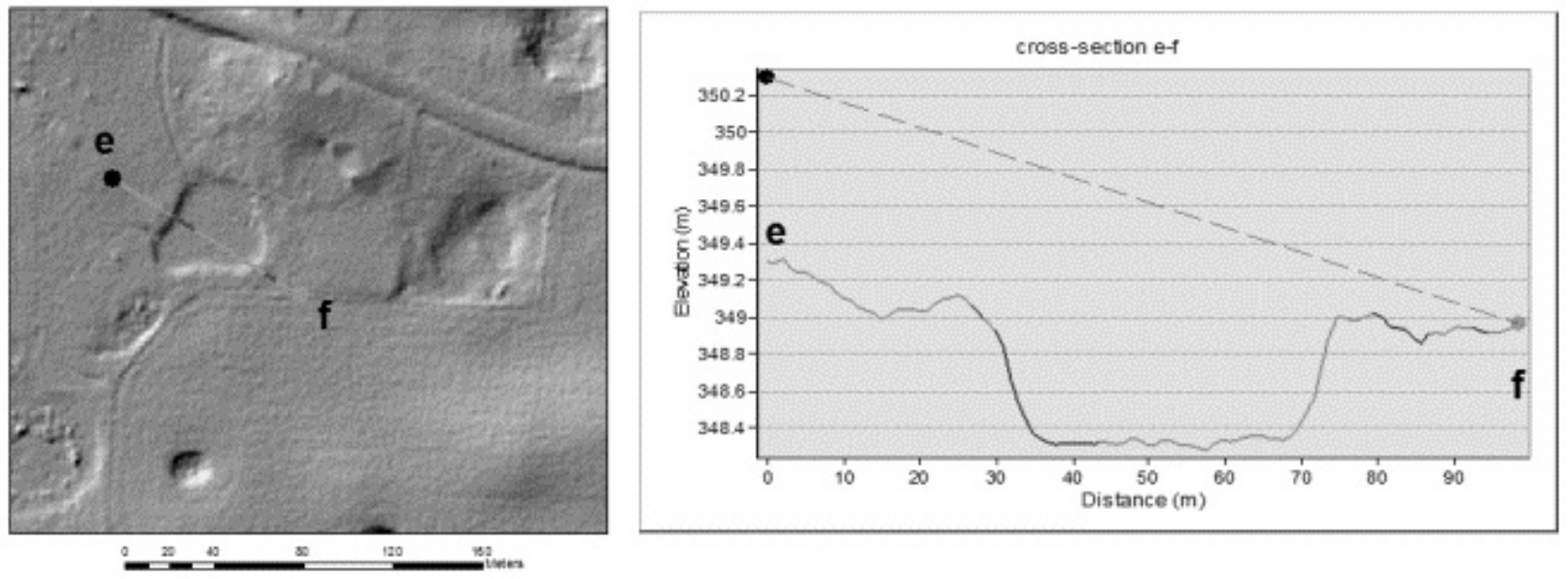

Figure 13. Sinkhole with an area of 1800 square meters and a depth of 0.46 meters is eliminated through pruning. 


\section{Conclusions}

The advent of high resolution LiDAR DEMs facilitates accurate and thorough sinkhole mapping. In the visual scanning process, comparing LiDAR data with KFDB classifies sinkholes into four groups: KFDB sinkhole locations which are the same as LiDAR locations; KFDB sinkhole locations slightly different from LiDAR data; KFDB sinkhole locations that are not visible on LiDAR; and additional sinkholes which are not listed in the KFDB. Comparison of these two data sets indicates that Winona County probably contains up to four times as many additional sinkholes as are indicated in the KFDB.

To improve the speed and efficiency of sinkhole mapping, an algorithm was developed to detect sinkholes automatically. To assess this method, selected regions in southwestern Winona County were analyzed. First, the erosion function in MATLAB® ${ }^{\circledR}$ was used to find seed points on LiDAR DEMs. Then, the active contour method was applied to identify depression boundaries based on seed points. Next, the list of potential sinkholes was characterized. Finally, a threshold was set, using the relationship between area and depth, to distinguish true sinkholes from other local depressions. After this pruning, the precision shows that $82 \%$ of detected sinkholes are true sinkholes and the remainders are false positives, compared to sinkholes that were field-located and in the KFDB. The majority of the false positives appear to be located along natural watercourses, ditches or roads or in quarries. Additionally, this automatic method finds $91 \%$ of sinkholes correctly, and misses only $9 \%$ of sinkholes detected in the field.

Considering the region to which the method was applied, with a variety of features (such as wetlands, woods, natural watercourses, ditches, quarries and manmade features), the precision and recall is sufficiently reasonable to map sinkholes.

In future work, this method will be applied for other areas of Winona County, the results will be compared with the KFDB, the LiDAR DEMs will be visually scanned and then all features identified will be field checked.

\section{Acknowledgments}

Funding for this project was provided by the Minnesota Environment and Natural Resources Trust Fund as recommended by the Legislative-Citizen Commission on Minnesota Resources (LCCMR).

\section{References}

ESRI, 2012. ArcGIS. Redlands (CA): Environmental System Research Institute. Available from: http:// www.esri.com/software/arcgis/arcinfo/index.html

Balaban NH, Olsen BM. 1984. C-02 Geologic Atlas of Winona County, Minnesota. Minnesota Geological Survey. $8 \mathrm{p}$.

Bing Map available at: http://www.bing.com/maps/

Dalgleish JB. 1985. Sinkhole distribution in Winona County, Minnesota [master's thesis] . Minneapolis (MN): University of Minnesota. 95 p. + map.

Filin S, Baruch A. 2010. Detection of sinkhole hazards using airborne laser scanning data. Photogrammetric Engineering \& Remote Sensing, 76 (5): 577-587.

Gao Y, Alexander EC Jr, Tipping RG. 2002. The development of a karst feature database for southeastern Minnesota. Journal of Cave and Karst Studies. 64 (1): 51-57.

Google Earth. Available from: http://www.google.com/ earth/index.html

Loesch T. 2009. Southeast Minnesota LiDAR project completed. MN GIS/LIS News 58, p. 1113. Available from: http://www.mngislis.org/ displaycommon.cfm?an=1\&subarticlenbr $=515$

Hedges J, Alexander EC Jr. 1985. Karst-related features of the Upper Mississippi Valley Region. Studies in Speleology. 6: 41-49.

Kass M, Witkin A, Terzopoulous, D. 1988. Snakes: active contour models. International Journal of Computer Vision 1 (4): 321-331.

Magdalene S, Alexander EC Jr. 1995. Sinkhole distribution in Winona County, Minnesota revisited. In: Beck BF, editor. Karst Geohazards: Engineering and Environmental Problems in Karst Terrane. Proceedings of the Fifth Multidisciplinary Conference on Sinkholes and the Engineering and Environmental Impacts of Karst;. 1995 Apr. 2-5; Gatlinburg, Tennessee. Rotterdam (NL): A.A. Balkema. p. 43-51.

Xu C, Prince JL. 1998. Snakes, shapes, and gradient vector flow. IEEE Transactions on Image Processing 7(3): 359-369. 
